\title{
Analisis Penokohan Tokoh Ainun dalam Novel Habibi dan Ainun Karya Baharudin Jusuf Habibi
}

\author{
Herni Fitriani \\ STKIP Nurul Huda OKU Timur, Sumatera Selatan \\ *E-mail: hfitriani4@gmail.com
}

\begin{abstract}
Abstrak
Literature generally involves all aspects of human life and life, events in works of fiction as well as events in everyday life, always carried by a certain character or perpetrators. The formulation of the problem in this analysis is how the characterization of Ainun figure is expository and dramatic in novel Habibie and Ainun Karya Bacharuddin Jusuf Habibie ?. The results of data analysis and discussion, In revealing the figure Ainun figure, the author uses the technique of depiction of figures proposed by Nurgiyantoro, the technique of depiction of characters in a literary work can be distinguished in two techniques, namely expository techniques and dramatic techniques, through the technique of Ainun figure expression in novel Habibie and Ainun by Bacharuddin Jusuf Habibie can be concluded that he is a figure of a very patient, while through dramatic techniques that include skillful techniques, behavioral techniques, techniques of mind and feeling, stream of consciousness techniques, reaction techniques, techniques of reactions of other figures, background and techniques of physical representation, figure Ainun is obedient and obedient to her husband, kind, responsible, has a very patient personality, he is a figure of a figure who likes peace, peace. But he had tested his loyalty to the husband that when he had to live mediocre when he was in Germany, he learned to use the maximum time so that everything can be resolved properly set the menu cheap but healthy, take care of children, husband and work. All he lived with full sincerity. Ainun always provide peace in his family with his personality. After a long time he thought to go back to work as a doctor so he could help his family's economy, but it takes recognition of UI diplomas in Germany and requires an indeterminate time process. After Ainun got back to work, Ainun was confronted with her personal problems when the children were sick and needed her to choose between work and children, based on faith, Ainun sacrificed her job as a doctor to Always be with her son and husband.
\end{abstract}

Kata kunci: Character Analysis, Novelist.

\section{PENDAHULUAN}

Sastra pada umumnya melibatkan segala aspek hidup dan kehidupan manusia, peristiwa dalam karya fiksi seperti halnya peristiwa dalam kehidupan sehari-hari, selalu diemban oleh tokoh atau pelaku-pelaku tertentu. Pelaku yang mengemban peristiwa dalam cerita fiksi sehingga peristiwa itu mampu menjalin suatu cerita disebut dengan tokoh. Sedangkan cara pengarang menampilkan tokoh atau pelaku itu disebut dengan penokohan. Tokoh cerita (character), menurut Abrams (dalam Nurgiyantoro, 2007:165) adalah orang - orang yang ditampilkan dalam suatu karya naratif, atau drama, yang oleh pembaca ditafsirkan memiliki kualitas moral dan kecenderungan tertentu seperti yang diekspresikan dalam ucapan dan apa yang dilakukan dalam tindakan.

Penelitian karya sastra secara mendalam diperlukan ilmu bantu. IImu bantu yang dipergunakan yakni ilmu pelukisan tokoh. Hal ini mengingat karya sastra merupakan aktivitas dalam suatu karya sastra, yaitu ketika pengarang melukiskan watak dan pribadi tokoh yang ditampilkan atau dihadirkannya dan menggambarkan tokoh yang dikehendakinya. Aminuddin (2011:96) menyatakan bahwa "pelaku yang mengemban peristiwa dalam cerita fiksi sehingga peristiwa itu mampu menjalin sutu cerita disebut dengan tokoh".

Pengarang akan menggunakan cipta, rasa, dan karya dalam berkarya. Begitu pula pembaca, dalam menanggapi karya juga tak akan lepas dari pelaku masing-masing, karakteristik kepribadiannya, penokohan mengenal karya sastra sebagai peranan pelaku yang berbeda-beda. 
Pengarang akan menangkap gejala perbedaan antar tokoh kemudian diolah menjadi sebuah teks dilengkapi dengan karakteristiknya. Proyeksi pengalaman sendiri dan pengalaman hidup di sekitar pengarang, akan terproyeksi secara imajiner ke dalam teks sastra.

\section{METODE/EKSPERIMEN}

Metode yang digunakan dalam penelitian ini adalah metode kualitatif yang bersifat deskriptifdengan bentuk content analysis atau analisis isi. Menurut Endraswara (2008:161) "Content analysis atau analisis isi adalah strategi untuk menangkap pesan (makna) karya sastra". Berdasarkan pendapat tersebut dapat disimpulkan bahwa metode penelitian kualitatif yaitu data-data yang dikumpulkan berupa kata-kata, dan bukan angka-angka. Dengan demikian, laporan penelitian akan berisi kutipan-kutipan data untuk memberi gambaran penyajian laporan tersebut.

Subjek dalam penelitian ini adalah novel Habibie dan Ainun karya Karya Bacharuddin Jusuf Habibie diterbitkan oleh PT THC Mandiri, tebalbuku 323 halaman. Objek dalam penelitian ini adalah penokohan tokoh dalam novel Habibie dan Ainun karya Karya Bacharuddin Jusuf Habibie.

Sumber Data

Menurut Arikunto (2013:172)"Sumber data dalam penelitian adalah subjek dari mana data dapat diperoleh". Subjek yang digunakan adalah novel Habibie dan Ainun karya Bacharuddin Jusuf Habibie. Sumber data dalam penelitian ini dibagi menjadi dua, yaitu.

a. Sumber data primer

Sumber data primer yang digunakan dalam penelitian ini yaitu novel Habibie dan Ainun karya Karya Bacharuddin Jusuf Habibie yang diterbitkan oleh PT THC Mandiri, tebal 323 halaman.

b. Sumber data sekunder

Sumber data sekunder yang digunakan dalam penelitianyaitu buku-buku yang membahas tentang novel serta teori analisis pelukisan tokoh.

Instrumen Penelitian

Penelitian kualitatif, yang menjadi instrumen atau alat penelitian adalah peneliti itu sendiri (Sugiyono, 2015:305). Instrumen dalam penelitian ini adalah peneliti sendiri sebagai alat pengumpul data dengan cara mengamati dan mengobservasi subjek penelitian yang dalam penelitian ini adalah novel Habibie dan Ainun karya Karya Bacharuddin Jusuf Habibie. Karena subjek penelitian adalah novel dan sumber data berupa dialog dalam novel, maka diasumsikan bahwa data itu sudah tersedia.

Teknik pengumpulan data yang peneliti digunakan adalah teknik dokumentasi. Dokumentasi digunakan untuk mengumpulkan data deskriptif analisis. Hal tersebut sebagaimana dikemukakan Margono (2010:181) bahwa "Teknik dokumentasi digunakan dengan cara mengumpulkan data melalui berbagai peninggalan tertulis termasuk buku-buku tentang pendapat, teori, bacaan seperti novel dan sebagainya". Teknik dokumentasi dilakukan melalui langkah-langkah sebagai berikut.

a. Membaca literatur utama yaitu buku referensi tentang teori pendekatan pelukisan karakter.

b. Membaca novel berjudul "Habibie dan Ainun" karya Bacharuddin Jusuf Habibie secara cermat, teliti, dan berulang-ulang untuk memahami teks dan penokohan tokoh.

c. Melakukan pencatatan terhadap aspek-aspek yang akan diteliti dari novel "Habibie dan Ainun" karya Bacharuddin Jusuf Habibie.

d. Mendata hal-hal penting dalam novel "Habibie dan Ainun" karya Bacharuddin Jusuf Habibie kemudian dicatat dalam kartu data.

e. Data terkumpul di dokumentasikan untuk dipergunakan sebagai sumber informasi.

Teknik Analisis Data

Analisis data adalah proses mengorganisasikan dan mengurutkan data ke dalam pola, kategori satuan uraian dasar sehingga dapat ditemukan tema seperi disarankan oleh data. Sesuai jenis 
penelitian digunakan yaitu penelitian deskriptif analisis, maka analisis data yang digunakan adalah analisis isi atau content analysis. Menurut Endraswara (2008:161) "Content analysis atau analisis isi adalah strategi untuk menangkap pesan (makna) karya sastra. Analisis ini dilakukan dengan cara menganalisis berbagai teks literatur hasil dokumentasi untuk dikembangkan menjadi pengetahuan baru.Berdasarkan penjelasan tersebut, analisis penokohan tokoh Ainun dalam novel Habibie dan Ainun karya Bacharuddin Jusuf Habibie dilakukan melalui langkah-langkah berikut.

a. Membaca dengan seksama novel yang sedang dianalisis yaitu "Habibie dan Ainun" karya Bacharuddin Jusuf Habibie.

b. Mengklasifikasikan dan memilah-milah data berupa teknik ekspositori dan teknik dramatik pada novel yang sedang di analisisyaitu "Habibie dan Ainun" karya Bacharuddin Jusuf Habibie.

c. Membuat hasil dari analisis data dalam novel kemudian disusun secara sistematis sehingga memudahkan dalam mendeskripsikan penokohan tokoh Ainun dalam novel Habibie dan Ainun karya Bacharuddin Jusuf Habibie.

d. Membuat kesimpulan dari analisis penokohan tokoh Ainun dalam novel Habibie dan Ainun karya Bacharuddin Jusuf Habibie.

\section{HASIL DAN PEMBAHASAN}

Hasil

Sebagaimana telah dikemukakan sebelumnya bahwa penokohan adalah ilmu yang mempelajari tentang bagaimana cara pengarang menampilkan tokoh atau pelaku dalam suatu cerita seperti halnya peristiwa dalam kehidupan sehari-hari. Sehingga dapat dianalisis menggunakan pendekatan pelukisan karakter. Adapun tokoh yang dianalisis dalam novel Habibie dan Ainun karya Bacharuddin Jusuf Habibie ini yaitu tokoh Ainun. Dalam mengungkap penokohan tokoh Ainun, penulis menggunakan teknik pelukisan tokoh yang dikemukakan oleh Nurgiantoro. Menurut Nurgiyantoro (2007:194) teknik pelukisan tokoh dalam suatu karya sastra dapat dibedakan dalam dua teknik, yaitu:

a. Teknik Ekspositori

Teknik ekspositori yang sering juga disebut sebagai teknik analitis merupakan pelukisan tokoh cerita yang dilakukan dengan memberikan deskripsi, uraian, atau penjelasan secara langsung (Nurgiyantoro, 2007:195). Tokoh cerita hadir dan dihadirkan oleh pengarang kehadapan pembaca secara tidak berbelit-belit, melainkan begitu saja dan langsung disertai deskripsi kehadirannya yang mungkin berupa sikap, sifat, watak, tingkah laku, atau bahkan juga ciri fisiknya. Contoh kutipan ekspositori dalam novel Habibie dan Ainun karya Bacharuddin Jusuf Habibie dijelaskan sebagai berikut.

Tabel: 1. Analisis Data

\begin{tabular}{|c|c|c|}
\hline $\begin{array}{l}\text { Teknik-teknik } \\
\text { Pelukisan } \\
\text { Karakter }\end{array}$ & Penggunaan dalam Kalimat & Analisis \\
\hline $\begin{array}{l}\text { Teknik } \\
\text { Ekspositori } \\
\text { BAB I }\end{array}$ & $\begin{array}{l}\text { "Terkenang tujuh tahun yang lalu ketika } \\
\text { Ainun sedang duduk bersama dari kelasnya } \\
\text { menikmati sarapan pagi bersama, tiba-tiba saya } \\
\text { datang mengucapakan kepada Ainun: "Mengapa } \\
\text { kamu begitu hitam dan gemuk?" Ainun pada } \\
\text { waktu itu hanya kaget saya datangi dan } \\
\text { mengucapakan pertanyaan yang tidak sopan itu. } \\
\text { ia dan kawan-kawannya hanya tersenyum dan } \\
\text { menggelengkan kepala saja" (Habibie, 2010:2) }\end{array}$ & $\begin{array}{l}\text { Berdasarkan kutipan } \\
\text { tersebut dapat diketahui bahwa } \\
\text { tokoh Ainun dalam kutipan ini, } \\
\text { merupakan sosok seorang tokoh } \\
\text { yang selalu sabar. Karena saat } \\
\text { habibie yang tiba-tiba muncul dan } \\
\text { memberikan pertanyaan yang } \\
\text { sedikit menghina Dia, Ainun } \\
\text { hanya membalas dengan } \\
\text { menggelengkan kepala dan } \\
\text { senyuman. }\end{array}$ \\
\hline
\end{tabular}




\section{b. Teknik Dramatik}

Penampilan tokoh ceria dalam teknik dramatik, artinya mirip dengan yang ditampilkan pada drama, dilakukan secara tak langsung, (Nurgiantoro, 2007:198). Artinya, pengarang tidak mendeskripsikan secara eksplisit sifat dan sikap serta tingkah laku tokoh. Pengarang membiarkan (baca: menyiasati) para tokoh cerita untuk menunjukan kediriannya sendiri melalui berbagai aktivitas yang dilakukan, baik secara verbal lewat kata maupun nonverbal lewat tindakan atau tingkah laku, dan juga melalui peristiwa yang terjadi.

\section{Pembahasan}

Penokohan dalam sebuah karya sastra baru mempunyai nilai artistik jika ia menambah koherensi dan kompleksitas karya sastra tersebut, artinya bahwa karya sastra dianggap sebagai hasil aktivitas dan ekspresi manusia, sedangkan penokohan itu dapat membantu pengarang dalam mengentalkan kepekaan dan memberikan kesempatan untuk menjajaki pola-pola yang belum pernah terjamah sebelumnya.

Penelitian karya sastra secara mendalam diperlukan ilmu bantu. IImu bantu yang dipergunakan yakni ilmu pelukisan penokohan. Hal ini mengingat karya sastra merupakan aktivitas karakter, yaitu ketika pengarang melukiskan watak dan pribadi tokoh yang ditampilkan atau dihadirkannya dan menggambarkan tokoh yang dikehendakinya. Berdasarkan hasil analisis data menggunakan teknik ekspositori dan teknik dramatik, penokohan tokoh Ainun dalam novel Habibie dan Ainun karya Bacharuddin Jusuf Habibie, dia merupakan sosok tokoh yang baik hati, Istri yang patuh terhadap suami tidak hanya istri kepada suami tetapi sebaliknya suami terhadap istri, cerdas, memiliki rasa tanggungjawab terhadap segala sesuatu yang dia memiliki, sosok yang sangat penyayang kapada anak dan suaminya dan berdasarkan latar tempat yang telah digambarkan, dia merupakan sosok seorang tokoh yang menyukai ketenangan, kedamaian serta rasa peduli yang begitu kuat, Dengan pemahaman seperti ini keluarga yang diinginkan menjadi keluarga yang Mawaddah Warahmah akan terwujud. Karena ketika laki-laki dan perempuan akan berkomitmen menjadi sepasang suami istri mereka harus mempunyai pemahaman bahwa ikatan keluarga bukan hanya istri kepada suami tetapi suami kepada istri, kehidupan keluarga seperti inilah yang dijalani Ainun dan Habibie sehingga keluarga mereka terkenal harmonis yang patut dicontoh.

Namun Ainun sempat diuji kesetiaannya kepada sang suami yakni saat dia harus hidup paspasan saat berada di Jerman, dia belajar menggunakan waktu secara maksimal sehingga semuanya dapat terselesaikan dengan baik mengatur menu murah tapi sehat, mengurus anak, suami dan pekerjaan, betapa Ainun sangat mendukung pekerjaan dan tugas Habibie dengan tanpa mengeluh selalu mencoba melakukan tugas dan kegiatannya dengan sebaiknya tanpa menganggu konsentrasi perhatian dan pekerjaan Habibie. Memberikan masukan intelektual dan pertimbangan juga saran yang saling mendukung satu sama lain. Selalu menjaga dan mengontrol kesehatan Habibie dengan menyediakan makanan sehat juga senyum menawan yang selalu dirindukan Habibie. Sebaliknya Habibie selalu melibatkan Ainun dalam setiap kegiatannya, menceritakan dan meminta pertimbangan istrinya untuk setiap keputusan yang akan di ambil. Benar-benar berpaduan yang harmonis, indah Romantis atas dasar cinta.

Ditinjau dari aspek positif yaitu Ainun merupakan sosok perempuan yang sangat mudah bergaul, mau bermusyawarah, bijaksana dan empati, mencintai keluarga, dan menghargai orang lain dan rendah hati. Dengan keluarganya Ainun sangat bijaksana dan penyayang memperhatikan setiap kebutuhan yang diperlukan anggota keluarga kecilnya. Bukan hanya pada keluarganya saja Ainun berbuat demikian namun juga pada orang lain/masyarakat ia sangat perhatian. Ainun selalu memberikan kedamaian dalam keluarganya dengan kepribadian yang dimilikinya.

Ainun juga menghadapi masalah pribadi saat ia harus memilih antara pekerjaan dan anak, berdasarkan kayakinan, Ainun mengorbankan pekerjaannya sebagai dokter untuk selalu ada bersama anak dan suaminya. Bentuk visualisasi dari adanya tekanan secara pelukisan tokoh dalam 
diri tokoh Ainun yaitu adanya perilaku, ditunjukan Ainun saat ia harus mengorbankan hobi dan pekerjaannya sebagai dokter. semua itu dia visualisasikan melalui tingkah laku verbal dan non verbal. Tingkah laku verbal yang dia tunjukan dengan mengatakan bahwa sebenarnya "la sangat ingin bekerja untuk membantu suami untuk menambah penghasilan". Sedangkan tingkahlaku non verbal yang dia tunjukan dia meninggalkan pekerjaan dan hobinya demi keluarga.

\section{Kesimpulan}

\section{PENUTUP}

Berdasarkan hasil analisis data dan pembahasan, Dalam mengungkap penokohani tokoh Ainun, penulis menggunakan teknik pelukisan tokoh yang dikemukakan oleh Nurgiyantoro, teknik pelukisan tokoh dalam suatu karya sastra dapat dibedakan dalam dua teknik, yaitu tehnik ekspositori dan tehnik dramatik, melalui teknik ekspositori tokoh Ainun dalam novel Habibie dan Ainun karya Bacharuddin Jusuf Habibie dapat disimpulkan bahwa dia merupakan sosok tokoh yang sangat sabar, sedangkan melalui teknik dramatik yang meliputi teknik cakap, teknik tingkah laku, teknik pikiran dan perasaan, teknik arus kesadaran, teknik reaksi tokoh, teknik reaksi tokoh lain, teknik pelukisan latar dan teknik pelukisan fisik, tokoh Ainun merupakan sosok yang patuh dan taat terhadap suaminya, baik hati, bertanggung jawab, memiliki kepribadian yang sangat sabar, dia merupakan sosok seorang tokoh yang menyukai ketenangan, kedamaian. Namun dia sempat diuji kesetiaannya kepada sang suami yakni saat dia harus hidup pas-pasan ketika berada di Jerman, dia belajar menggunakan waktu secara maksimal sehingga semuanya dapat terselesaikan dengan baik mengatur menu murah tapi sehat, mengurus anak, suami dan pekerjaan.

Setelah sekian lama dia berpikir untuk kembali bekerja sebagai dokter agar dia bisa membantu perekonomian keluarganya, tetapi butuh pengakuan ijazah UI di Jerman dan membutuhkan proses waktu yang tak tentu. Setelah melalui banyak proses akhirnya Ainun bisa kembali bekerja, Kemudian Ainun dihadapkan dengan masalah pribadinya saat anak-anak sakit dan membutuhkannya ia harus memilih antara pekerjaan dan anak, berdasarkan kayakinan, Ainun mengorbankan pekerjaannya sebagai dokter untuk selalu ada bersama anak dan suaminya.

\section{Saran}

Berdasarkan simpulan tersebut, penulis mengemukakan beberapa saran sebagai berikut.

1. Bagi pengajar Bahasa dan Sastra Indonesia, dan orang-orang yang memahami sastra. Novel Habibie dan Ainun karya Bacharuddin Jusuf Habibie sangat baik untuk dibaca karena peran tokoh dalam novel ini sangat layak untuk diteladani. Pengorbananya dalam membangun keluarga demi mewujudkan keluarga yang sakinah, mendidik anak dengan baik, serta saling mendukung profesi yang dimiliki masing-masing tokoh.

2. Bagi penggemar karya sastra khususnya novel, hendaknya lebih banyak membaca novelnovel yang bercerita tentang sisi kehidupan sehingga dapat diambil makna dan nilai-nilai yang terkandung dalam novel tersebut.

3. Penelitian mengenai penokohan tokoh Ainun dalam novel Habibie dan Ainun karya Bacharuddin Jusuf Habibie hendaknya dapat dijadikan contoh untuk penelitian lebih lanjut di bidang sastra. 
22 | Seulas Pinang: Jurnal Pendidikan Bahasa dan Sastra, Vol. 1 No. 1,Halaman: 17 - 22, Oktober, 2019

\section{DAFTAR PUSTAKA}

Aminudin. 2011. Pengantar Apresiasi Karya Sastra. Bandung: Sinar Baru Agresindo.

Arikunto, Suharsimi. 2013. Prosedur Penelitian Suatu Pendekatan Praktek. Jakarta: PT. Renika Cipta.

Endarswara, Suwardi. 2008. Metodelogi Penelitian Sastra. Jakarta: Medpress (Anggota IKAPI).

Departemen Pendidikan Nasional 2008. Kamus Besar Bahasa Indonesia. Jakarta: PT Gramedia Pustaka Umum.

Gerungan, W. A. 2010. Psikologi Sosial. Bandung: Eresco.

Habibie, B. J. 2010. Habibie dan Ainun. Jakarta: PT THC Mandiri.

Kosasih, E. 2012. Dasar-dasar Ketrampilan Berbahasa. Bandung:Yrama Widya.

Lexy. J. Moleong. 2010. Metodelogi Penelitian Kualitatif. Bandung: Reremaja Rosda Karya.

Margono, S. 2010. Metodelogi Penelitian Pendidikan. Jakarta: Rineka Cipta.

Nurgiyantoro, Burhan. 2007. Teori Pengkajian Fiksi. Yogyakarta: Gajah Mada.

STKIP. 2014. Pedoman Akademik STKIP Nurul Huda. Bandung:Alfabeta.

Walgito, Bimo. 2010. Pengantar Psikologi Umum. Yogyakarta: Andi.

Wellek, Rene, dan Agus Warren. 2014. Teori Kesusastraan. Jakarta: Gramedia Pustaka Umum. 